\title{
Recursos didácticos para el aprendizaje de la educación comercial: Sistematización de una experiencia en educación superior
}

\author{
Teaching Resources for Commercial Education Learning: A Higher Education Learning \\ Experience Systematization
}

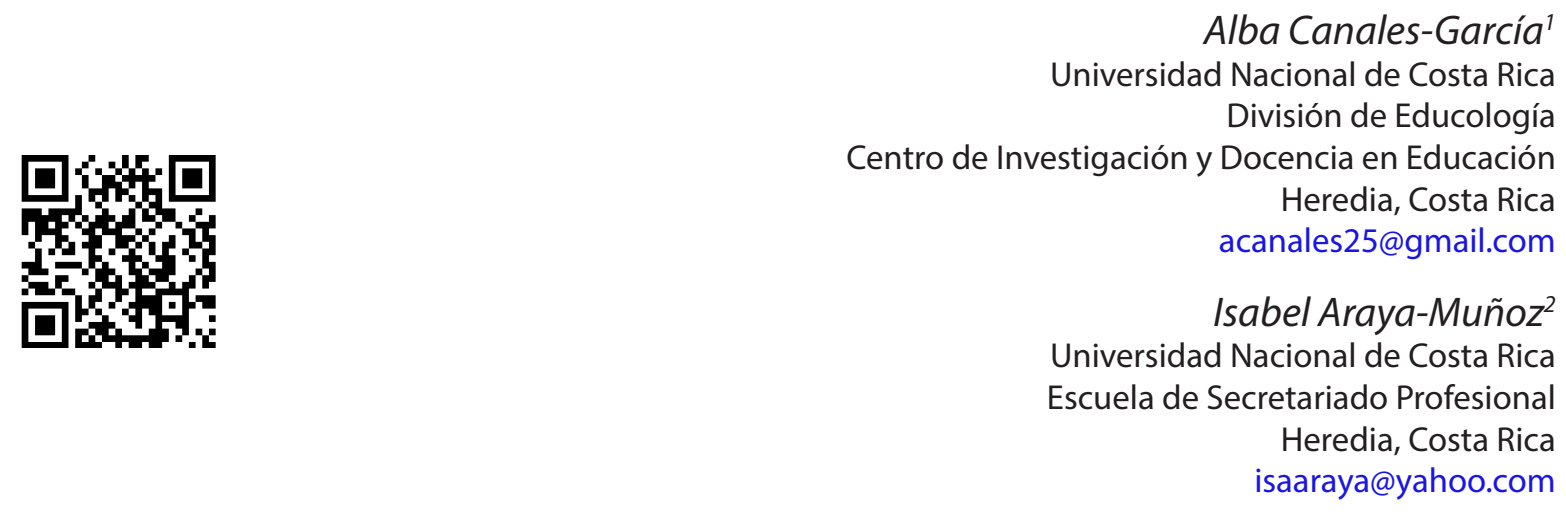

Recibido 15 de diciembre de 2015 • Corregido 17 de febrero de 2017 • Aceptado 18 de abril de 2017

Resumen: La presente sistematización de experiencias en la asignatura Recursos Didácticos para el Aprendizaje de la Educación Comercial, en la titulación de la Licenciatura de Educación Comercial, tiene como objetivo analizar la función docente y su interrelación con la utilidad y pertinencia que se le da a las tecnologías de la información y comunicación (TIC) en la especialidad de secretariado. La metodología consistió en elaborar dispositivos didácticos con tecnologías y recursos tradicionales, así como observar clases en instituciones de secundaria en donde se imparte la especialidad del secretariado. Esta última condujo a la elaboración de propuestas didácticas a cargo del grupo estudiantil. El proceso de sistematización se llevó a cabo desde el enfoque cualitativo. Los principales hallazgos demuestran que la mayoría de docentes no utilizan las TIC para el desarrollo de recursos didácticos para el aprendizaje. El estudiantado apunta a la necesidad de hacer clases más interactivas con el apoyo tecnológico. Se espera que la presente sistematización sirva de insumo para motivar a docentes y estudiantes de la enseñanza y a reconocer la necesidad de actualizarse e innovar las clases con nuevas tecnologías.

Palabras claves: Tecnologías de la información y comunicación; educación comercial; sistematización de experiencias; recursos didácticos, innovación.

\footnotetext{
${ }^{1}$ Master en Docencia Universitaria, Licenciada en Educación Comercial, Experto en E-Learning. Actualmente académica en la División de Educología, así como coordinadora en el Proyecto Aprender y Enseñar en la Virtualidad, de la Universidad Nacional.

2 Master en Planificación Curricular de la Universidad de Costa Rica, Master en Docencia Universitaria de la Universidad Nacional, Licenciatura en Educación Comercial. Actualmente académica de la Escuela de Secretariado en la Universidad Nacional.
} 
doi: http://dx.doi.org/10.15359/ree.21-2.7

URL: http://www.una.ac.cr/educare

CORREO: educare@una.cr

\begin{abstract}
This systematization of experiences in the course "Teaching Resources for Commercial Education Learning" mainly aims to analyze the teacher role and the relation with the utility and pertinence given to the Information and Communication Technologies (ICT) in the secretarial major. This course is part the bachelor's degree program in Commercial Education. The methodology consisted in elaborating teaching devices with traditional technology and resources, as well as observing high school lessons where the secretarial major was taught. The observations led the students to elaborate teaching proposals. A qualitative approach was used during the systematization process. The main findings show that most of the teachers do not use ICT as teaching resources in their classes. Students pointed out to the need for having more interactive lessons with the help of technological devices. Through this systematization it is expected that teachers and students will be motivated to use and recognize the need to innovate their classes with new technologies.
\end{abstract}

Keywords: information and communications technologies (ICT), commercial education, experience systematization, teaching and learning resources, innovation.

\title{
Introducción
}

El uso que se les da a las TIC como recursos didácticos en el aula universitaria está condicionado por algunos elementos: a) disposición e interés del personal docente en formación en aprender acerca de las nuevas tecnologías educativas, b) los recursos económicos y tiempo que dedique la institución o el propio personal docente en capacitarse, c) disposición al cambio, y d) tomar nuevos riesgos.

La ausencia de esos elementos limita la innovación didáctica, con la consecuencia de una enseñanza expositiva y transmisora de contenidos; se recurre al uso del texto impreso como única fuente de conocimiento, en la mayoría de los casos con fotocopias, una proyección con diapositivas que reproduce la teoría, el uso de pizarra y el dictado. De acuerdo con las autoras, el rol que la mayoría de docentes emplea en el salón de clases es dirigente, autoritario, estático (sentado en el escritorio); y el estudiantado organizado en los pupitres en forma lineal: eso ha perdurado por muchos años.

El uso de TIC en el aula universitaria no implica, per se, un cambio didáctico; requiere un análisis de la aplicación de las herramientas tecnológicas y la base comunicativa subyacente en las interacciones que se dan en el proceso de enseñanza-aprendizaje. Al respecto, España y Canales (2013) señalan la importancia de compartir conocimientos, promover el trabajo en grupos y la investigación, el pensamiento crítico.

La sistematización de esas experiencias didácticas conlleva a la reflexión y a la mejora, de acuerdo con Jara (2012), permite el análisis de lo vivido, los procesos y los factores que intervinieron, sus relaciones y apreciaciones, a partir del diario de cada docente, de los datos que aporta el estudiantado en las diferentes actividades de aprendizaje, así pues, es posible reconstruir los significados, posterior a la ejecución del curso; de esa manera se llega al análisis crítico de la práctica para proponer ideas innovadoras. 
En ese sentido, este artículo busca la reflexión sobre cómo utilizar las TIC con fines educativos y su relación con enfoques didácticos contemporáneos, a partir de la sistematización de experiencias de la asignatura Recursos Didácticos para el Aprendizaje de la Educación Comercial, en el ámbito de la Universidad Nacional de Costa Rica.

\section{Referentes teóricos}

La educación es un derecho fundamental del ser humano; a través de ella es posible alcanzar niveles de desarrollo para el bienestar individual y de la sociedad; en ese sentido, sus fines más profundos están en la persona, sus capacidades, sus necesidades y su entorno vivencial y futuro profesional. Esas son características de un modelo didáctico que integra la institución educativa, al personal docente, estudiantes y su contexto.

La sistematización de experiencias es una práctica que se sustenta en los principios de la educación integral basada en el holismo, filosofía que, según Martínez (2000, p. 34): "es un proceso natural de la mente humana y, por ello, indispensable e, incluso, imprescindible como ideal o utopía inalcanzable, pero orientadora en todos los aspectos de la vida humana". Desde esa perspectiva, el tema de la educación ha sido estudiado desde diversos enfoques. Ruiz (2007), cuya propuesta desde la pedagogía de la resocialización, se basa en principios de responsabilidad, conciencia y libertad para formar seres humanos para vivir responsablemente en una cultura emergente sostenible. Pardo $(2001$, p. 23$)$ apunta a un proceso educativo holístico que distingue las diferentes facetas de la persona: "lo cognitivo, lo afectivo y lo social"; García (2015) plantea una serie de principios pedagógicos universitarios, cuya esencia es la persona y su transformación como ser individual y social; Castillo y Marín (2009) proponen, en educación universitaria, una perspectiva holística para integrar la vida y el conocimiento.

Así, pues, la educación basada en el holismo considera en el proceso de enseñanzaaprendizaje todos esos elementos de la convivencia del ser humano con su entorno; debido a ello, el proceso didáctico debe ser abordado desde paradigmas pedagógicos cognoscitivos y constructivistas, cuya base filosófica y epistemológica se opone a la transmisión de datos y a la determinación social. Por esa razón, el sustento didáctico se fundamenta en la didáctica activa; es decir, el centro es el estudiantado, sus intereses y necesidades en torno a una futura profesionalización, así como para un desempeño exitoso en su vida personal y en sociedad.

En ese contexto, el rol de los actores tiene una nueva disposición que Gallegos (1999, p. 39) destaca en los siguientes términos:

Desde la educación holista, aprender es un proceso que implica muchos niveles de la conciencia humana como el afectivo, físico, social y espiritual ... Aprender se convierte en proceso creativo y artístico; aprender a aprender es el propósito de la educación para el siglo XXI. 
doi: http://dx.doi.org/10.15359/ree.21-2.7

URL: http://www.una.ac.cr/educare

CORREO: educare@una.cr

Entonces, el currículo debe ser diseñado y aplicado considerando los principios filosóficos, psicológicos y sociales; en contraste con la educación tecnocentrista y economicista, el enfoque educativo holístico aporta a la didáctica y se aprecian nuevos caminos a partir del trabajo en colaboración, la indagación y la autonomía, con el propósito de transformar, así, la realidad de sus artífices. La formación profesional desde esa visión de la educación no implica abandonar los fines educativos intelectuales, económicos, sociales y tecnológicos, sino más bien integrar la vivencia, en la que docente y estudiante se involucren con su aporte individual y en equipo para el logro de aprendizajes significativos para su vida futura profesional.

Son varios los modelos pedagógicos con enfoque holístico que se han propuesto en el ámbito educativo, y que involucran sistematización de experiencias educativas. Las características fundamentales de esos trabajos se enfatizan en el desarrollo del potencial humano con sus diversas capacidades individuales y sociales. Salas, Rojas y Jiménez (1998) hacen alusión a los modelos de Sonnier (1982), Rinke (1982), Klimek (1976) y el de McCarthy $(1981,1990)$. La propuesta de Sonnier integra la enseñanza y el aprendizaje, en cuyo proceso se destacan los roles activos y participativos tanto del personal docente como del estudiantado, orientados a resultados cognoscitivos y afectivos. El modelo de Rinke enfatiza en las estrategias de enseñanza-aprendizaje, de acuerdo con las necesidades del estudiantado y su potencial de aprender en forma permanente. La idea de Klimek busca la integración de las experiencias desde toda la dimensión humana (cuerpo, mente, emociones, imaginación, voluntad, entre otras). El enfoque de McCarthy es relevante en el uso del cerebro en su totalidad, al aplicar los diferentes estilos de aprendizaje.

En ese proceso, las nuevas TIC contribuyen en la organización de materiales, coordinación y gestión de las diferentes actividades didácticas. En el caso de los procesos de enseñanzaaprendizaje de educación comercial, aportan formas de innovación didáctica en las diferentes áreas de conocimiento; esas herramientas permiten procesos informativos (datos e información), de comunicación entre personas y de colaboración, en cuyos ambientes virtuales se puede dar, de manera sincrónica o asincrónica, mediante herramientas para lograr productividad.

Si bien es cierto uno de los fines de la formación universitaria es preparar personas para una vida profesional futura con competencias que les permitan competitividad en sus campos de trabajo, esa formación debe estar permeada por lo que apunta Ruiz (2015, p. 39): "formar profesionales críticos, capaces no sólo de asimilar tecnologías sino de crearlas y de asumir posiciones transformadoras en todos los campos de su vida personal y social".

En esa línea, los recursos tecnológicos son medios auxiliares que, mediante materiales y herramientas, favorecen el proceso de enseñanza-aprendizaje en términos de hacer más atractivas, interesantes y significativas las clases; por eso los medios y recursos son instrumentos que ilustren temas y permitan una comprensión idónea de la relación teoría-práctica. Al respecto, 
Cabero (2007) anota que las TIC ofrecen entornos de aprendizaje que permiten la disposición de información de forma rápida y actualizada, variedad de posibilidades de acceso, de generación y transmisión de información y de conocimientos (imagen, sonido, movimiento, etc.).

Por tanto, el potencial de los recursos tecnológicos como medios didácticos es positivo porque permite generar cambios e innovación educativa, sin perder de vista que los principios pedagógicos y la base epistemológica, como apunta Lion (2000), orientan, en algunos casos, decisiones políticas, ideológicas y pedagógicas, pero también generan mitos sobre la analogía entre nuevos medios y las transformaciones.

La educación comercial, de acuerdo con Araya (2012), refiere a la promoción de espacios pedagógicos para el desarrollo de competencias profesionales, orientadas a la gestión de apoyo administrativo y secretarial, sustentado en disciplinas de desarrollo humano, comunicación en inglés y en español, secretariado, psicología, educación, investigación, cultura general, derecho, archivística, tecnológicas de la información, y la comunicación y gestión empresarial. Ese espacio profesional de la docencia se encarga de formar personal técnico-profesional en las especialidades de administración de oficinas, gestión secretarial ejecutiva, atención de centros de servicio al cliente y diversas tareas de apoyo logístico y administrativo.

La planificación de la enseñanza en educación comercial, al igual que en otras áreas de la instrucción, toma en cuenta, en su organización, las características del estudiantado, el soporte del recurso y la intención didáctica para su uso; de ahí la importancia de diferenciar la funcionalidad de los más utilizados, sin olvidar el avance permanente de la tecnología, según se detalla a continuación:

- Gráficos (pizarra, mapas, imágenes, rotafolio o papelógrafo, láminas y carteles...).

- Materiales impresos (libros, antologías, unidades didácticas, prácticas para realizar en clase...).

- Multimedia (televisión, vídeos, música...)

- Aplicaciones y web 2.0 (Aplicaciones computacionales: procesador de textos -Word u otro-, hoja electrónica -Excel u otra-, bases de datos -Access u otros-, presentaciones -Power Point, Prezi, etc. -, mapas conceptuales -Cmap tools, etc.-; recursos en línea: correo electrónico, foros, chats, wikis, etc.-, teléfono móvil -mensajes SMS o llamadas, WhatsApp-; recursos colaborativos en línea como Google Drive, Writebord, Audacity, Linoit, Issuu, etc. -web 2.0-, video-YouTube, música, etc.-, libros o revistas electrónicas, enciclopedias en línea o en CD-ROM, web, blogs, etc.; redes sociales -Facebook, Twiter, etc.-; videotutoriales...)

- Plataformas enseñanza virtual (Moodle, Claroline, Blackboard...) 
doi: http://dx.doi.org/10.15359/ree.21-2.7

URL: http://www.una.ac.cr/educare

CORREO: educare@una.cr

Así pues, con el avance del conocimiento en términos de diferenciar las formas de enseñar y de aprender, así como la evolución de los recursos tecnológicos mecánicos e informatizados, resalta la importancia de considerar criterios pedagógicos para su selección y uso; de esta manera, García (2003) recomienda tomar en cuenta el tipo de recurso, la concepción educativa que fundamenta el espacio educativo, los objetivos de aprendizaje y la visión pedagógica de cada docente para facilitar el acceso a estos.

La exclusividad de un enfoque puro de educación holista no es la fórmula idónea, sino que a partir de lo que llamaremos didáctica holística se retoman ideas fundamentales de construcción de aprendizajes con mayor significado en la integración de saberes en el proceso pedagógico. Así como se esquematiza en la Figura 1, el proceso se inicia con unos objetivos como meta de aprendizaje del estudiantado, estos, más que objetivos del curso, se plantean en función del sujeto aprendiente; unos contenidos temáticos que corresponden a los fundamentos teóricos y prácticos que permiten identificar y conjugar con la realidad; las estrategias de enseñanzaaprendizaje, como proceso dinámico sustentadas en la interacción, el diálogo y el acercamiento al contexto del estudiantado, la autonomía y el trabajo colaborativo en una dualidad docenteestudiante; y la estrategia de evaluación, como parte del proceso de aprender, con técnicas de seguimiento permanente de manera formativa y sumativa, para el reforzamiento y la mejora.

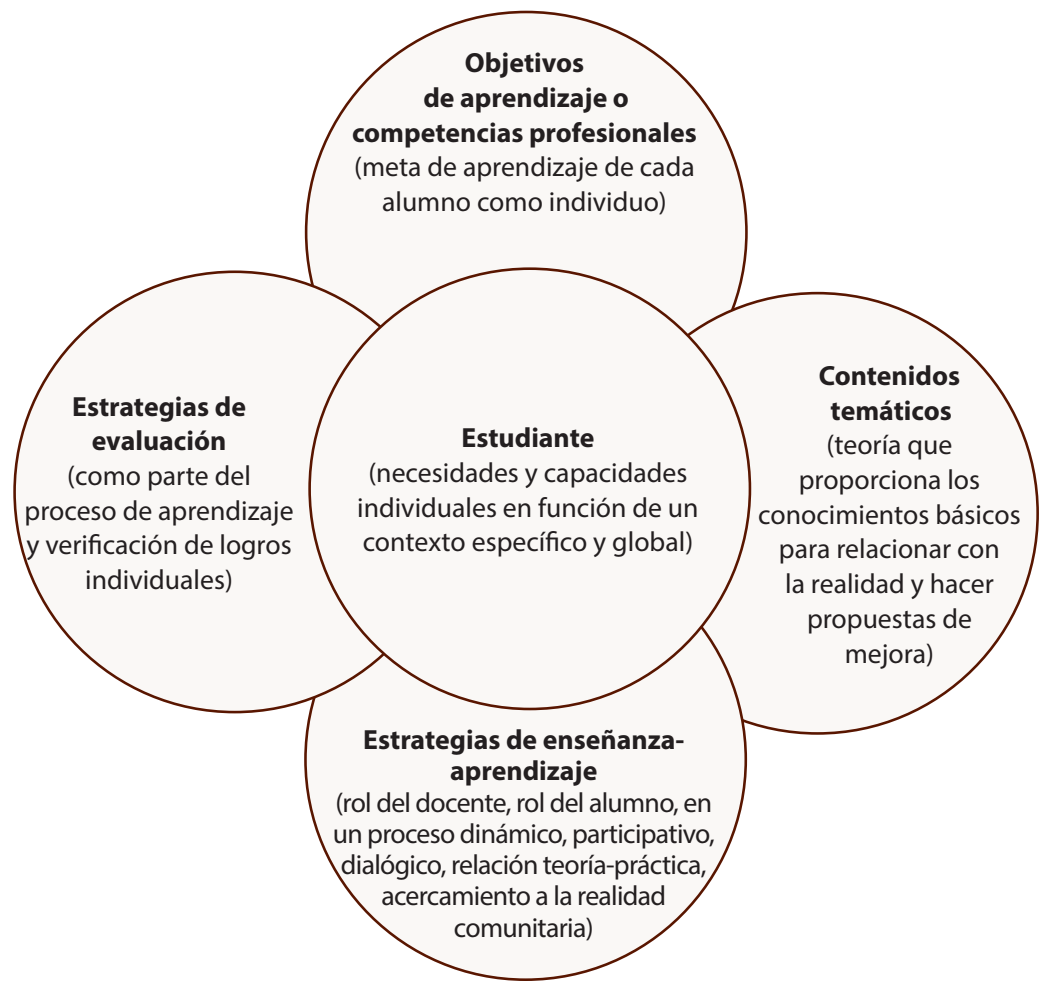

Figura 1: Integración de saberes en un proceso de enseñanza-aprendizaje. Nota: Adaptación de Soler, Soler y Araya (En prensa). 
Por tanto, como referente para este trabajo, la didáctica holística se concreta en cuatro elementos: a) docente con el rol de guía, quien estimula el desarrollo de las potencialidades del estudiantado y se apoya en el uso de nuevos recursos que propicien el aprendizaje significativo; b) trabajo colaborativo en el aula; es decir, dar confianza al estudiantado para que manifieste sus ideas, de tal manera que se promueva un ambiente agradable y participativo, y pueda construir desde sus conocimientos, dado que gran parte tiene acceso a materiales que otra parte no conoce; c) disposición de medios y recursos didácticos en el aula y fuera de ella, por lo que es tarea docente dedicar tiempo para prepararlos; e) apoyo familiar, en varios aspectos, afectivos y económicos, para que el estudiantado pueda salir adelante en la carrera seleccionada.

\section{Método}

Este estudio se llevó a cabo a partir de la sistematización de experiencias, método que permite la reconstrucción y reflexión analítica (Tabares, Molina y Cuervo, 2014). De acuerdo con Jara (2012), el análisis de experiencias educativas desde una perspectiva cualitativa, con uso de técnicas e instrumentos de corte cualitativo (lista de cotejo, encuesta, diario de clase, matriz y palabra e imagen), permite interpretar los significados de los agentes activos en los procesos de enseñanza-aprendizaje; esos criterios los comparte también Pérez (1994).

El contexto de estudio fue elegido por conveniencia, en vista de que las investigadoras forman parte del equipo de la asignatura Recursos Didácticos para el Aprendizaje de la Educación Comercial. Esta asignatura forma parte de la malla curricular de la titulación de grado Licenciatura en Educación Comercial, que se imparte en la Universidad Nacional de Costa Rica en coordinación entre unidades académicas (Escuela de Secretariado Profesional para las materias específicas de Educación Comercial y la División de Educología para las materias didáctico-pedagógicas), la modalidad presencial y con apoyo tecnológico del aula virtual. En esta experiencia participó un grupo de 19 estudiantes con edades entre los 19 y 22 años.

El propósito de esa asignatura es que el estudiantado conozca, analice y utilice los recursos didácticos tradicionales y modernos más adecuados para el futuro desarrollo de sus clases como docentes en educación técnica profesional.

Las fuentes de información se detallan en la matriz de recolección de datos, según Tabla 1. 
doi: http://dx.doi.org/10.15359/ree.21-2.7

URL: http://www.una.ac.cr/educare

CORREO: educare@una.cr

Tabla 1: Matriz de recolección de información

\begin{tabular}{|c|c|c|c|}
\hline Técnica & Fuentes & Instrumentos & Procedimientos \\
\hline $\begin{array}{l}\text { Visita a instituciones } \\
\text { educativas }\end{array}$ & $\begin{array}{l}10 \text { grupos, de las asignaturas de: } \\
\text { - Comunicación empresarial } \\
\text { - Administración de oficinas } \\
\text { - Técnicas de oficinas } \\
\text { - Destrezas computacionales } \\
\text { - Estadística descriptiva }\end{array}$ & $\begin{array}{l}\text { - Hoja de cotejo } \\
\text { - Informe de } \\
\text { observación }\end{array}$ & $\begin{array}{l}\text { Se realizó observación de clase de } 10 \\
\text { grupos, en } 10 \text { colegios, } 8 \text { son colegios } \\
\text { técnicos profesionales y dos colegios } \\
\text { técnicos profesionales de adultos } \\
\text { (institutos profesionales de educación } \\
\text { comunitaria), todos del sector público } \\
\text { costarricense. }\end{array}$ \\
\hline Foro de discusión & Estudiantado de la asignatura & Foros virtuales & $\begin{array}{l}\text { En estas actividades programadas en } \\
\text { el aula virtual, el estudiantado tenía } \\
\text { la oportunidad de compartir algunas } \\
\text { lecturas complementarias a los temas } \\
\text { que se estaban desarrollando, y el } \\
\text { análisis de contenido de los productos. } \\
\text { Cada foro tenía una guía, instrucciones } \\
\text { y fechas de lo que debían realizar. En el } \\
\text { diario de clase se anotaba cada sesión } \\
\text { y lo realizado (nivel de complejidad del } \\
\text { recurso y reflexiones finales). }\end{array}$ \\
\hline $\begin{array}{l}\text { Técnica palabra e } \\
\text { imagen }\end{array}$ & Estudiantado de la asignatura & $\begin{array}{l}\text { Hoja con } \\
\text { instrucciones }\end{array}$ & $\begin{array}{l}\text { El estudiantado, por medio de un } \\
\text { dibujo y palabras, expresó el antes y } \\
\text { el después de la asignatura Recursos } \\
\text { Didácticos para el Aprendizaje de la } \\
\text { Educación Comercial. }\end{array}$ \\
\hline \multirow[t]{2}{*}{$\begin{array}{l}\text { Grupo de } \\
\text { discusión }\end{array}$} & Estudiantado de la asignatura & $\begin{array}{l}\text { Guía de } \\
\text { preguntas } \\
\text { generadoras }\end{array}$ & $\begin{array}{l}\text { Mediante el conversatorio guiado } \\
\text { por la docente, con el grupo de } \\
\text { estudiantes, se analizó en una sesión } \\
\text { presencial, en el aula de clases, la } \\
\text { experiencia llevada a cabo durante } \\
\text { el curso lectivo de la asignatura, las } \\
\text { preguntas generadoras fueron: }\end{array}$ \\
\hline & & & $\begin{array}{l}\text { - ¿qué aprendió en el curso? } \\
\text { - ¿qué fue lo más importante de lo } \\
\text { aprendido y cómo lo aplica en su vida? } \\
\text { • ¿qué recomendaciones haría al curso? }\end{array}$ \\
\hline
\end{tabular}

Nota: Elaboración propia.

La validez de los datos analizados se sustenta en la triangulación teórica y el control cruzado entre las investigadoras para validar el contenido, para evitar, así, las posibles fuentes de error (Pérez, 1994). 


\section{Resultados}

La asignatura en estudio se llevó a cabo en el segundo ciclo 2014 y de acuerdo como se detalla en la Tabla 2, las actividades desarrolladas se muestran en tres fases. La primera comprendió la teoría y la práctica sobre recursos, exposiciones grupales y trabajos en el aula virtual; la segunda, observación y valoración de recursos que se podrían implementar de acuerdo con el contenido que se estaba ejecutando; y la tercera, en realizar un proyecto final en el que se retomaran los conocimientos adquiridos en el curso, con una entrega escrita y la socialización en clase.

Tabla 2: Fases del proceso de enseñanza-aprendizaje. Asignatura Recursos Didácticos para el Aprendizaje de la Educación Comercial

\begin{tabular}{|c|c|c|}
\hline & Actividades & Categorías analizadas \\
\hline $\begin{array}{l}\text { Fase } 1 . \\
\text { Teoría y práctica }\end{array}$ & $\begin{array}{l}\text { Talleres sobre recursos didácticos } \\
\text { tradicionales y modernos: } \\
\text { - Recursos tradicionales: rotafolio, cartel, } \\
\text { tablero mágico, uso de la pizarra, } \\
\text { collage, títeres...) } \\
\text { - Recursos tecnológicos informatizados: } \\
\text { página web, revista digital, Google Drive, } \\
\text { blog, Voky, Movie-Maker, Linoit, Examtime, } \\
\text { Prezi, Dropbook, entre otros } \\
\text { - Exposiciones grupales creativas } \\
\text { acerca de los recursos tradicionales y } \\
\text { modernos: } \\
\text { - Explicación del recurso } \\
\text { - Elaboración de un planeamiento didáctico } \\
\text { - Taller (elaboración de recursos didácticos) } \\
\text { - Participación en el aula virtual (crítica, } \\
\text { fundamentada) } \\
\text { - Lecturas (foros, chat y tareas) } \\
\text { - Subida de trabajos de exposiciones } \\
\text { (link, texto, etc.) }\end{array}$ & $\begin{array}{l}\text { - Recursos didácticos tradicionales y } \\
\text { modernos. Relación entre el uso de } \\
\text { recursos didácticos y los estilos de } \\
\text { aprendizaje. } \\
\text { - } \quad \text { Recursos didácticos apropiados para } \\
\text { apoyar el proceso de enseñanza- } \\
\text { aprendizaje en Educación Comercial. } \\
\text { El uso del aula virtual en el proceso } \\
\text { de enseñanza-aprendizaje. }\end{array}$ \\
\hline $\begin{array}{l}\text { Fase } 2 . \\
\text { Elaboración y aplicación }\end{array}$ & $\begin{array}{l}\text { - Valoración de los diferentes recursos } \\
\text { didácticos. } \\
\text { - Propuesta de recurso que se puedan } \\
\text { utilizar en una clase en un colegio. } \\
\text { - Visita a una clase en un centro. }\end{array}$ & $\begin{array}{l}\text { - Cuáles recursos tecnológicos utilizan. } \\
\text { - Cómo los utiliza cada docente en su } \\
\text { clase. } \\
\text { - Ventajas y desventajas del uso de } \\
\text { los recursos didácticos en el aula de } \\
\text { Educación Comercial. } \\
\text { - Qué le gusta al estudiantado en } \\
\text { cuanto al uso de los recursos } \\
\text { didácticos. } \\
\text { - Recursos didácticos innovadores. }\end{array}$ \\
\hline
\end{tabular}


doi: http://dx.doi.org/10.15359/ree.21-2.7

URL: http://www.una.ac.cr/educare

CORREO: educare@una.cr

\begin{tabular}{|c|c|c|}
\hline & Actividades & Categorías analizadas \\
\hline $\begin{array}{l}\text { Fase } 3 . \\
\text { Proyecto didáctico }\end{array}$ & $\begin{array}{l}\text { Elaboración de un proyecto: blog, página } \\
\text { web, video educativo, revista, etc. } \\
\text { Trabajo escrito y socialización } \\
\text { de propuestas en la clase y a dos } \\
\text { instituciones. }\end{array}$ & $\begin{array}{l}\text { - Las TIC en educación comercial. } \\
\text { - Planeamiento didáctico holístico } \\
\text { para el proceso de enseñanza- } \\
\text { aprendizaje de la educación comercial. } \\
\text { Presentación de los recursos } \\
\text { - Innovar en el grupo. }\end{array}$ \\
\hline
\end{tabular}

La información sistematizada en las diferentes etapas se estructura de manera que responde a las siguientes preguntas generadoras:

- ¿Cuáles son los recursos didácticos más apropiados para el aprendizaje, según la naturaleza de las áreas de estudio, en educación comercial?

La práctica docente en educación comercial, en el contexto estudiado, destaca en el uso de los recursos tecnológicos tradicionales combinados con los electrónicos, los cuales se aplican de acuerdo con los contenidos que se aprenden en cada área de conocimiento y la disposición en cada centro. Esto se detalla en la Tabla 3.

Tabla 3: Recursos tecnológicos utilizados, según materia de conocimiento

\begin{tabular}{ll}
\hline Temas & Recurso que utiliza \\
\hline $\begin{array}{l}\text { Gestión empresarial: Elementos importantes en la } \\
\text { redacción de documentos (márgenes, pie de páginas, } \\
\text { entre otros). }\end{array}$ & Antología, pizarra, fotocopias de capítulos de libros. \\
\hline Destrezas computacionales: elaboración de informe. & $\begin{array}{l}\text { Presentación en Power Point, computadora, equipo } \\
\text { multimedia. }\end{array}$ \\
\hline Presupuesto: cómo calcular el aguinaldo & $\begin{array}{l}\text { Presentación en Power Point, computadora, equipo } \\
\text { multimedia, dictar las diapositivas. }\end{array}$ \\
\hline Tecnologías: notas al pie de página en un documento. & $\begin{array}{l}\text { Material fotocopiado (deteriorado y desactualizado), } \\
\text { práctica y computadoras. }\end{array}$ \\
\hline Etiqueta y protocolo & $\begin{array}{l}\text { Contenido teórico, prueba final: almuerzo para aplicar } \\
\text { lo visto en clase (platos, vasos, cubiertos...). }\end{array}$ \\
\hline
\end{tabular}

continúa... 


\begin{tabular}{ll}
\hline Temas & Recurso que utiliza \\
\hline Gestión empresarial: principios de la etiqueta en la empresa & $\begin{array}{l}\text { Equipo multimedia, computadora, pizarra, copias } \\
\text { sobre FODA, a partir de una empresa ficticia. }\end{array}$ \\
\hline $\begin{array}{l}\text { Técnicas de oficina (informes, curriculum vitae, } \\
\text { memorandos, cartas entre otros) }\end{array}$ & $\begin{array}{l}\text { Compendio elaborado por la docente, tutoriales (tipo } \\
\text { MecaNet), pizarra, carteles. }\end{array}$ \\
\hline Principios y prácticas contables & Pizarra, compendio de lecturas, Excel. \\
\hline Comunicación empresarial, tipos documentales (cartas) & $\begin{array}{l}\text { Antología, presentación en Power Point, televisor, } \\
\text { parlantes, lapiceros, marcadores, cinta adhesiva, } \\
\text { tijeras, algunos libros, hojas de colores y folletos. }\end{array}$ \\
\hline $\begin{array}{l}\text { Administración de oficinas: concepto y principios } \\
\text { generales de la administración. La oficina moderna. }\end{array}$ & $\begin{array}{l}\text { Pizarra, presentación en Power Point, papel periódico } \\
\text { y marcadores }\end{array}$ \\
\hline $\begin{array}{l}\text { Destrezas computacionales: posición correcta frente al } \\
\text { computador. Mobiliario ergonómico. Gimnasia para manos }\end{array}$ & $\begin{array}{l}\text { Laboratorio de informática, imágenes y papeles de } \\
\text { colores. }\end{array}$ \\
\hline $\begin{array}{l}\text { y hombros. Teclado numérico; } 4,7,3,8 ; 2,9,1,0 ; 5,6 . \\
\text { Cuestionario y entrevista. }\end{array}$ & $\begin{array}{l}\text { Material fotocopiado, pizarra acrílica, arcadores de } \\
\text { colores, cartulinas. }\end{array}$ \\
\hline
\end{tabular}

Nota: Datos según observación realizada por estudiantes.

La función de los medios y recursos tecnológicos responde a la intencionalidad pedagógica con que sean utilizados en el proceso didáctico. Noguez (2013) anota la importancia de que esos medios se utilicen con el propósito de generar aprendizajes específicos, faciliten la comprensión y la comunicación de los contenidos temáticos para que el proceso de aprender sea facilitado en su fase informativa, comprensiva y de aplicación.

\section{- ¿Cuáles son los recursos tecnológicos más utilizados por los docentes de Educación Comercial?}

Los recursos materiales que con mayor frecuencia utilizan los docentes de Educación Comercial en su práctica pedagógica son el material impreso, seguido de presentaciones en equipo multimedia. Se destaca que los recursos tradicionales son los que siguen predominando en el desarrollo de las lecciones, como se ilustra en la Figura 2. Estos datos concuerdan con (Cuevas y Álvarez, 2014, p. 14), quienes apuntan que, en su actividad cotidiana, el profesorado tiene una propensión relativamente baja al uso de recursos como "multimedia, pizarras electrónicas, televisores, software educativo, internet, etc."; tal y como se anota, la tendencia es el uso de recursos materiales impresos, situación que responde a las limitaciones de material didáctico electrónico, equipo y otros recursos tecnológicos. 
doi: http://dx.doi.org/10.15359/ree.21-2.7

URL: http://www.una.ac.cr/educare

CORREO: educare@una.cr

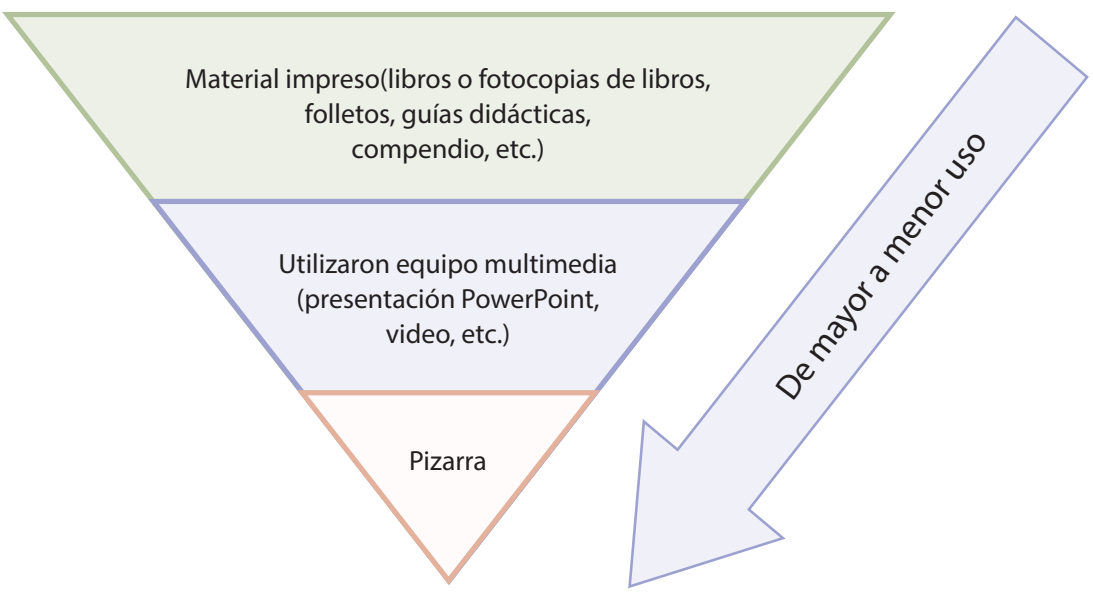

Figura 2: Frecuencia de uso de recursos tecnológicos.

Nota: Elaboración de las autoras con datos de observación.

\section{- ¿Cuál es la pertinencia de las TIC en la entrega docente?}

La pertinencia de los recursos tecnológicos de cualquier índole atiende tres aspectos didácticos: la intencionalidad pedagógica, el entorno y el soporte, los cuales se detallan en la tabla 4.

Tabla 4: Pertinencia de recursos

\begin{tabular}{|c|c|c|}
\hline \multirow{3}{*}{$\begin{array}{l}\text { Elementos didácticos } \\
\text { pertinentes en el uso de } \\
\text { los recursos tecnológicos } \\
\text { (mecánicos y electrónicos) }\end{array}$} & Intencionalidad pedagógica & $\begin{array}{l}\text { - proporciona información } \\
\text { - practica destrezas y habilidades } \\
\text { - actitudes y motivación } \\
\text { - evalúa conocimientos, destrezas y habilidades } \\
\text { - guía aprendizajes }\end{array}$ \\
\hline & Entorno de comunicación & $\begin{array}{l}\text { - contenido, estructura, representación. } \\
\text { - conos o símbolos: textuales, sonoros, visuales, etc. }\end{array}$ \\
\hline & Soporte material & - físico, software, medios de reproducción. \\
\hline
\end{tabular}

Nota: Datos según la opinión de docentes.

Esos elementos didácticos deben ser concordados con los objetivos de aprendizaje y planificar la estrategia de acuerdo con los niveles cognoscitivos (García, 2003), si se pretende proporcionar información (estrategia introductoria básica, particular, de fondo, conclusiva, etc.); si se pretende profundizar o aplicar (estrategia de discusión, análisis o aplicación: cuestionar, reiterar, contrastar, argumentar, ejemplificar, ejercitar, simular, etc.); si se pretende 
evaluar (estrategia evaluativa: diagnóstica, calificativa, etc.). Es decir, cada recurso posee su aplicación práctica, en ese sentido los recursos tecnológicos tienen su utilidad y función dentro del proceso didáctico.

El uso de recursos tecnológicos para innovar el proceso de enseñanza-aprendizaje involucra esfuerzo, dedicación y capacitación de parte del profesorado, por ello hay cierta resistencia a incluirlos en los planes de trabajo, así lo manifiesta el personal docente:

"Aprender a utilizar nuevos recursos es necesario para innovar y hacer las clases interesantes, para estar actualizado con los recursos propuestos." [E01]

"El uso de videos, tutoriales y juegos didácticos facilitan el aprender la materia y motiva a los estudiantes." [E02]

“Hace falta capacitación y actualización en uso de TIC, se evidencia limitación en cuanto al uso de los recursos." [E03]

“En los colegios hay limitaciones de acceso a internet y cuando utilizan tutoriales o programas en línea tienen problemas de conexión, eso es frustrante para el estudiantado y para el docente."

Existe cierta orientación hacia la clase magistral, si bien es cierto hay limitaciones tecnológicas, cuando se tiene a disposición se utiliza sin mayor planificación, lo cual lleva a la misma monotonía. De acuerdo con Ortiz (2007), prevalece la falsa creencia de que utilizar recursos telemáticos son el motor para la innovación y evitar la rutina; mientras que la mirada debería estar en la gestión del aprendizaje.

No obstante, la tendencia se vislumbra a la mejora, según indica el profesorado, hay posibilidades de mejora presupuestaria que viene a fortalecer los rubros de infraestructura, equipo y telecomunicaciones; asimismo, Cuevas y Álvarez (2014) confirman que las posibilidades y la disposición del profesorado de educación secundaria académica y técnica, en el ámbito costarricense, de incorporar las TIC al proceso educativo, van en aumento.

- ¿Cuáles son los recursos TIC más apropiados para el aprendizaje, según la naturaleza de las áreas de estudio, en educación comercial?

La selección de los recursos TIC en el proceso educativo no puede estar al azar pues debe haber una estrecha relación entre los contenidos de aprendizaje y cómo deben ser enfocados para que el estudiantado se informe, los comprenda y los pueda aplicar a su realidad profesional y luego evalúe su aplicación. En la Tabla 5 se reflejan algunos de los recursos que propone el estudiantado a partir de su propuesta. 
doi: http://dx.doi.org/10.15359/ree.21-2.7

URL: http://www.una.ac.cr/educare

CORREO: educare@una.cr

Tabla 5. Propuesta de recursos, para las clases observadas

\begin{tabular}{|c|c|c|}
\hline Subárea & Contenidos & Propuestas \\
\hline $\begin{array}{l}\text { Destrezas } \\
\text { computacionales }\end{array}$ & $\begin{array}{l}\text { 1. Técnicas de oficina (informes, } \\
\text { currículo vitae, memorandos, } \\
\text { cartas entre otros) } \\
\text { 2. Computador. Mobiliario } \\
\text { ergonómico. Gimnasia para } \\
\text { manos y hombros } \\
\text { 3. Teclado numérico }\end{array}$ & $\begin{array}{l}\text { - Video elaborado sobre normas APA. } \\
\text { - Ficha metodológica para cada estudiante } \\
\text { sobre lo que se debe realizar. } \\
\text { - Teclado de la computadora (a color, con las } \\
\text { diferentes teclas), elaborado con material } \\
\text { de desecho. El ejemplo del material que } \\
\text { elaboró la estudiante. } \\
\text { - Revista en ISSUU, en donde se } \\
\text { ejemplifiquen los diferentes documentos. }\end{array}$ \\
\hline Gestión empresarial & $\begin{array}{l}\text { 4. Calcular el aguinaldo, principios y } \\
\text { prácticas contables } \\
\text { 5. Concepto y principios generales } \\
\text { de la administración. La oficina } \\
\text { moderna } \\
\text { 6. Etiqueta y protocolo }\end{array}$ & $\begin{array}{l}\text { - Manual que explican el uso de Linoit (con el } \\
\text { fin de que la materia sea más agradable a la } \\
\text { vista para el estudiantado) y Google Drive. } \\
\text { - Rompecabezas y carpetas a partir de } \\
\text { material reciclable para ver los contenidos. } \\
\text { - Blog para ver definiciones, videos sobre } \\
\text { el tema. Se puede consultar en siguiente } \\
\text { enlace: http://educaetiqueta.blogspot. } \\
\text { com/?view=classic }\end{array}$ \\
\hline $\begin{array}{l}\text { Comunicación } \\
\text { empresarial y } \\
\text { administración de } \\
\text { documentos }\end{array}$ & $\begin{array}{l}\text { 7. Técnicas de comunicación (panel, } \\
\text { mesa redonda, foro...) } \\
\text { 8. Comunicación oral }\end{array}$ & $\begin{array}{l}\text { - Examtime (fichas), para ver definiciones, } \\
\text { pizarra acrílica hecha a partir de materiales } \\
\text { con reutilizables. } \\
\text { - Presentación en Prezi } \\
\text { - Cartel en forma de sobre con cada carta, } \\
\text { con la idea de que el estudiantado visualice } \\
\text { y ubique el tipo de carta. }\end{array}$ \\
\hline
\end{tabular}

Nota: Elaboración a partir de trabajos realizados por el estudiantado.

Dos ejemplos de recursos que propone el estudiantado, a partir del contraste de la teoría con lo observado en el contexto, son los mostrados en las figuras 3 y 4. 


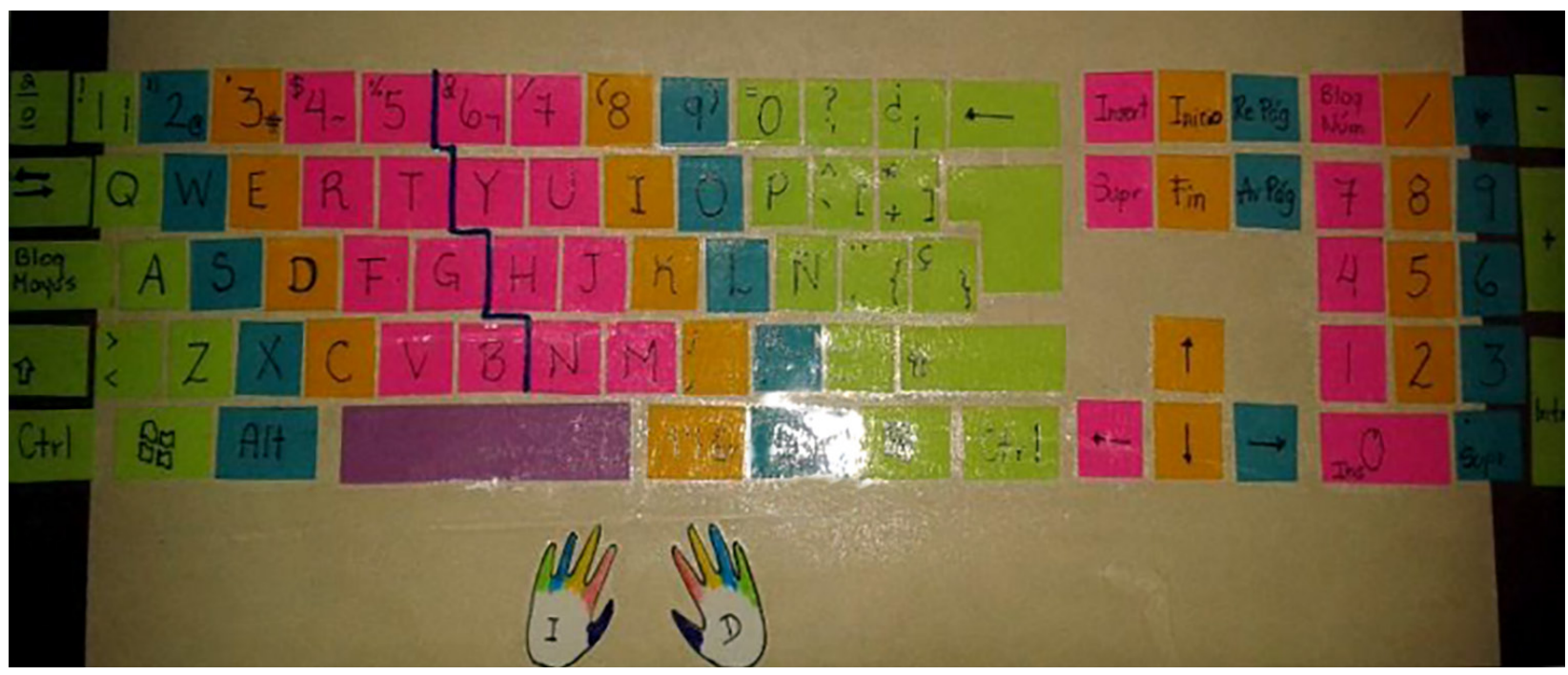

Figura 3: Recurso. Teclado elaborado con material de reciclaje.

- Aplicación: Aprendizaje del teclado, la posición correcta de los dedos y sirve para practicar los alcances alfabéticos, numéricos y de signos, así como las teclas de función, especiales y de dirección.

- Área de conocimiento: Destrezas computacionales

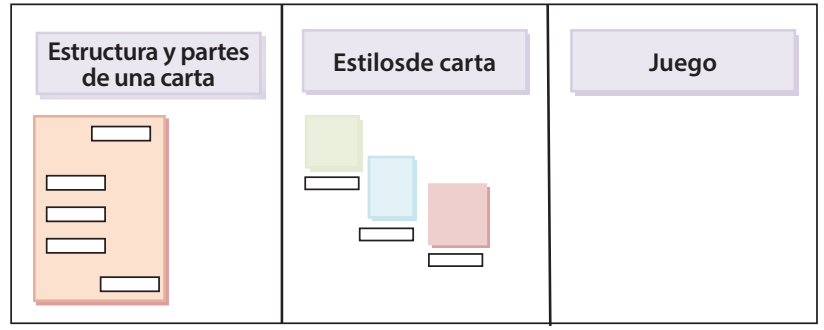

Figura 4: Recurso. Cartel, elaborado en cartulina.

- Aplicación: Elaborar material de apoyo para explicar la estructura, partes y estilo de las cartas; así como para realizar un ejercicio mediante un juego.

- Área de conocimiento: Destrezas computacionales 
doi: http://dx.doi.org/10.15359/ree.21-2.7

URL: http://www.una.ac.cr/educare

CORREO: educare@una.cr

\section{- ¿Cuáles son esas experiencias significativas para el estudiantado a partir de la asignatura?}

La tecnología didáctica orienta la planificación estructurada en forma horizontal, con el fin de dar igualdad de importancia a los elementos básicos del planeamiento didáctico: objetivoscontenidos-actividades de mediación-valores y actitudes-aprendizajes por evaluar. Si bien la planeación traza unas líneas generales que guían la entrega docente, no se deben descartar factores como los valores, actitudes, habilidades para la vida, uso de recursos, reflexiones sobre lo aprendido, aula virtual como una herramienta que permite gestionarla información, acercamiento a la realidad profesional futura, compañerismo, trabajo grupal e individual, aprovechamiento de nuevos recursos tecnológicos, preocupación por situaciones familiares, creatividad, curiosidad e interés por la investigación, y necesidad de acompañamiento individualizado.

En ese sentido, como actividad de cierre del curso, se le pidió al estudiantado que reflejara, mediante un dibujo, la experiencia vivida y la reflexión de lo aprendido, la cual interpretaron según se anotan algunos casos (ver figuras 5, 6, 7 y 8).

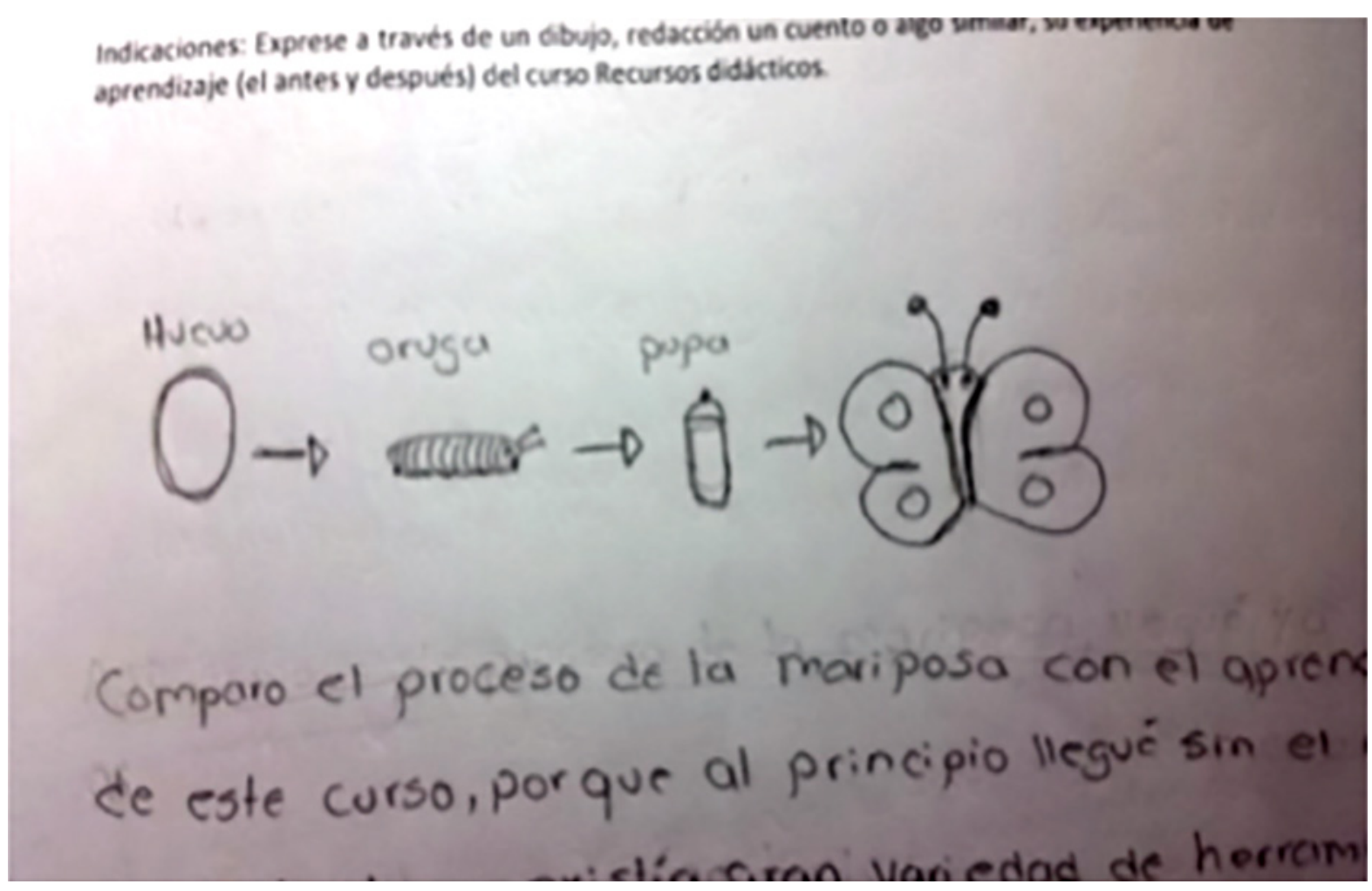

Figura 5: Interpretación. El dibujo expresa el proceso de la mariposa, cómo ha ido creciendo y pasando por las diferentes etapas de vida hasta transformarse en una bella mariposa que seguirá explorando e implementando en las futuras clases como estudiante. 
doi: http://dx.doi.org/10.15359/ree.21-2.7

URL: http://www.una.ac.cr/educare

CORREO: educare@una.cr

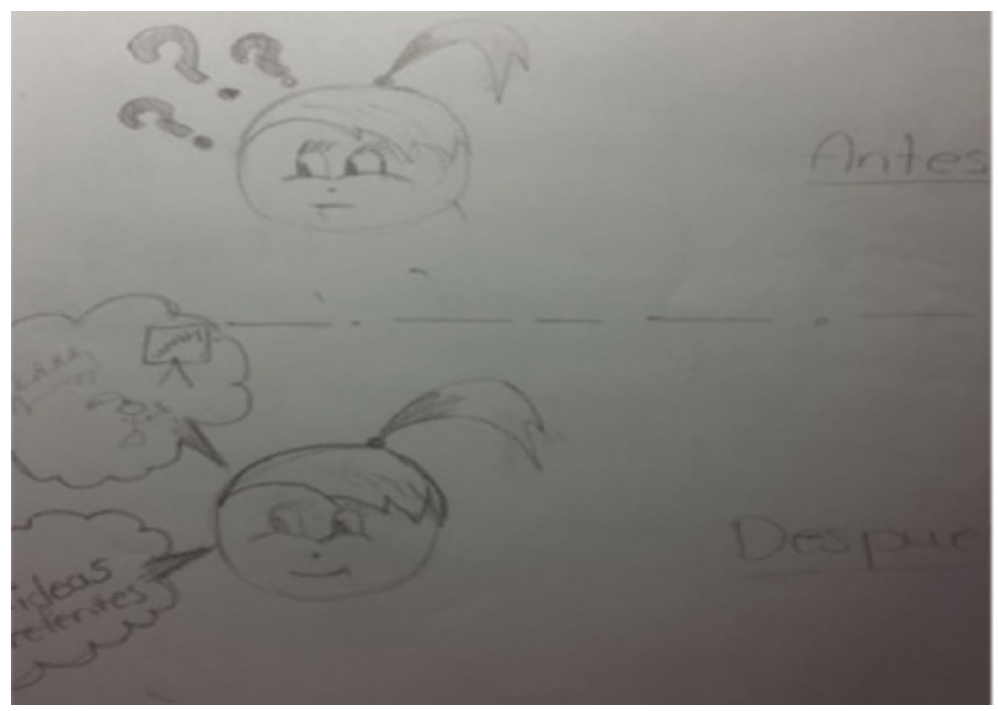

Figura 6: Interpretación. Representa el antes de una joven con signos de preguntas, y después con ideas diferentes, más claras.

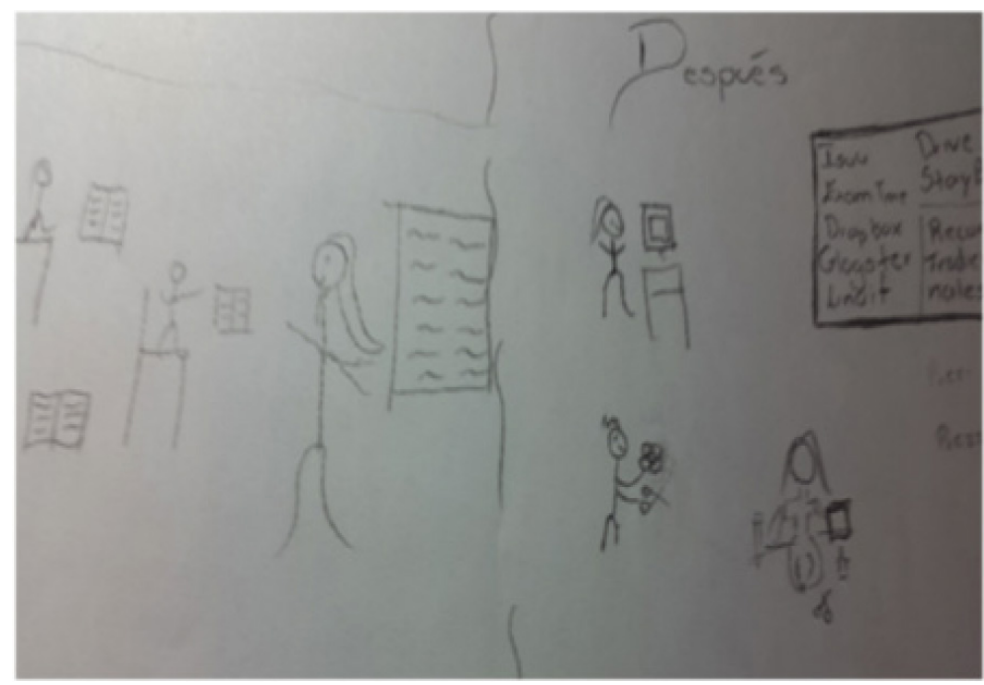

Figura 7: Interpretación. Representa el antes; es decir, la joven sentada en un pupitre, aburrida con libros, escuchando a la docente; y el después, con una serie de herramientas como:/ISSUU, Examtime, Dropbox, Globster, Linoit, Drive, Storybird, Prezi, que me han gustado y que son valiosas en mi futuro docente. 
doi: http://dx.doi.org/10.15359/ree.21-2.7

URL: http://www.una.ac.cr/educare

CORREO: educare@una.cr

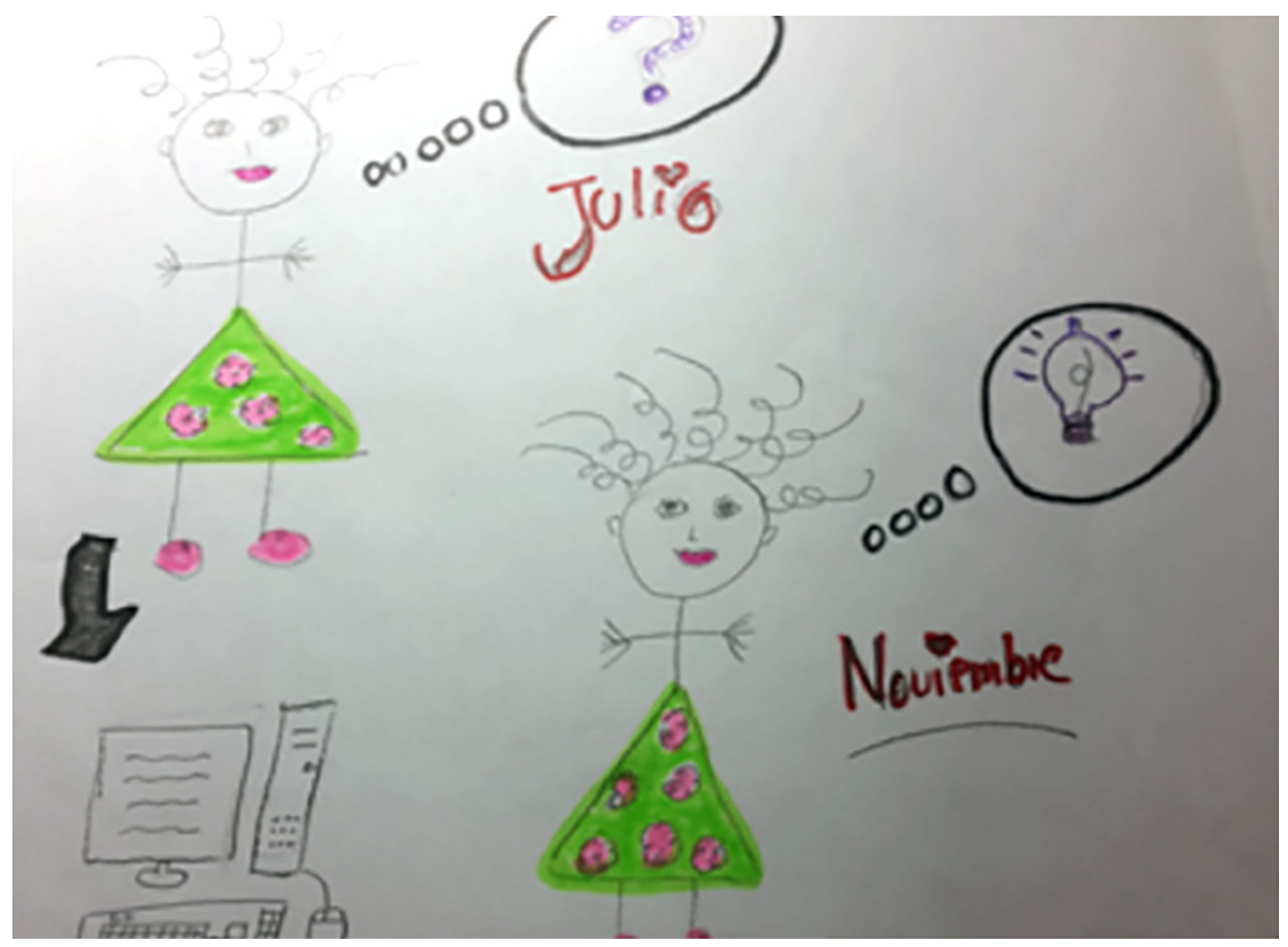

Figura 8: Interpretación. El mes de julio cuando inicié el ciclo lectivo, tengo dudas, expectativas, ilusiones. En noviembre tengo luz, me siento a gusto, libre con muchas ideas y conocimientos para poner en práctica.

Otras apreciaciones de estudiantes del curso universitario que es importante anotar son las siguientes:

- "Los recursos tecnológicos me ofrecen un mundo lleno de posibilidades".

- "No tenía idea de las cosas que podría realizar con la tecnología: ISSUU, Weebly, blogger, Globster, Voki, web, Story Bird, Prezi, Examtime, Drive y otros más han convertido mi creatividad".

- "Al inicio me sentía como una artista, pero no tenía materiales para expresar mi arte, ahora tengo muchos recursos para expresarse y encantar al mundo".

- "Me siento feliz, sus expectativas sobrepasan los límites porque ella ni imaginaba que esas cosas existían...." 
- "En el curso hemos aprendido a realizar clases más dinámicas para que los estudiantes aprendan haciendo, descubriendo y desarrollando destrezas y habilidades, pero por mis limitaciones materiales y de tiempo no logré lo esperado".

De la información analizada, se podría resaltar que los recursos tecnológicos son un apoyo importante en el plan didáctico de toda clase, siempre que se utilicen con una intencionalidad pedagógica; es decir, para fortalecer las capacidades individuales, la creatividad y la indagación.

A pesar de que las instituciones educativas no cuentan con recursos tecnológicos suficientes y actualizados, es relevante aprovechar el potencial de lo que se tenga a disposición y evitar así frases como "el cartel que usa la docente no se ve muy bien, no dan ganas de leer, la letra es muy pequeña"; eso llama a dedicar tiempo en la elaboración de material didáctico.

Conocer el uso y aplicación que se les puede dar a las nuevas herramientas tecnológicas hace que las clases sean más amenas y no se caiga en la monotonía:"la profesora sigue utilizando el mismo material en las clases desde hace tres años". Es pertinente motivar al futuro personal docente en educación comercial sobre la importancia de la actualización permanente, con recursos que puedan apoyar la labor académica, lo cual es un imperativo para innovar en el aula.

La educación holística se fundamenta en valores humanos, por ello tomar en cuenta al otro individuo y la calidez del trato deben estar siempre presentes en el futuro docente de educación comercial, dado que nunca se termina de aprender; así, cuando otras personas llegan a hacer observación de aula, es con el fin de actualizar, innovar el proceso de enseñanzaaprendizaje y no ver que ello represente una amenaza. En esta sistematización se constataron los recursos con fines didácticos que el mismo estudiantado puso en práctica en el desarrollo de sus clases, innovando a partir de ideas e iniciativas.

En ese sentido, las TIC, por sí solas, no aportan elementos que favorezcan la innovación. Para lograr un cambio es necesario promover la planeación estratégica, con el fin de seleccionar los recursos adecuados, indagar sobre las necesidades individuales del estudiantado, enfatizar en los objetivos de aprendizaje en torno al desarrollo de competencias profesionales. Con respecto al alumnado, promover la utilidad de hacer clases más interactivas, tanto en su quehacer estudiantil, de manera que posteriormente se mantenga actualizado sobre los nuevos recursos que podría utilizar en su práctica docente, sin descuidar la investigación.

\section{Consideraciones finales}

A partir de este proceso de sistematización, que conlleva a la reflexión de la propia didáctica de las profesoras investigadoras como las experiencias observadas a través de la mirada de estudiantes en investigación, surgen las siguientes ideas: 
doi: http://dx.doi.org/10.15359/ree.21-2.7

URL: http://www.una.ac.cr/educare

CORREO: educare@una.cr

El uso de recursos didácticos en educación comercial es una necesidad en los diferentes niveles tecnológicos: mecánicos, electrónicos e interactivos en la web, por tanto, su uso mediador entre la meta educativa, las competencias que se pretende lograr y las actividades de aprendizaje y de evaluación, son un medio no un fin, y para su incorporación apropiada se debe trabajar desde la didáctica.

La motivación del estudiantado es fundamental para que proponga y elabore material a partir de la realidad educativa a la que se enfrenta. La idea de que el estudiantado realice propuestas de recursos didácticos conlleva a que se observen directamente desde el espacio de aula, su futuro contexto laboral, le permite ver la realidad, ver cómo los cuerpos docentes en ejercicio trabajan los temas, las dinámicas de clase, las diferencias individuales entre estudiantes, las limitaciones materiales; en fin, ese millar de elementos que se presentan en el día a día en el salón de clase les hace reflexionar sobre las necesidades de creatividad e innovación. Un grupo de estudiantes planteó y realizó hasta tres propuestas de los recursos que podrían implementarse en el desarrollo de la clase observada.

El estudiantado manifiesta que los recursos que más prevalecen en la clase observada fueron el uso de antologías, material fotocopiado y presentaciones en PowerPoint, y los grupos docentes justifican que por falta de tiempo no pueden capacitarse, porque en el colegio no les dan permiso, o bien, porque no les interesa utilizarlas en las clases porque prefieren seguir con las clases tradicionales. Este es un tema que hay que profundizar.

La pertinencia de las tecnologías en el desarrollo de las clases es importante, dado que propicia nuevas formas de aprender, de enseñar, dejando de lado recursos obsoletos que puedan desmotivar en el proceso de aprendizaje. Estudiantes que asisten en horarios diurnos son jóvenes que les gusta ver cosas nuevas que les generen expectativas, interés y motivación por aprender. Con base en lo anterior, hay que responder a esa necesidad.

En esta experiencia se describe cómo las iniciativas de que el estudiantado, futuro profesional en docencia en educación comercial, a partir de la visita a colegios y practicar no solo aprende, sino que los grupos docentes propietarios interactúan con nuevos conocimientos teóricos y se da un encuentro academia-empresa, similar a la educación dual (Araya, 2008) o bien a la relación experiencia-realidad (Dewey, 1960), tan importante en la academia. Por ello, es un proceso de realimentación tanto para el futuro personal docente, como para el que está en ejercicio, porque propone y se actualiza con nuevas metodologías de enseñanza, las cuales pueden estar al alcance global, sin generar gastos en el espacio educativo.

El estudiantado que ha participado en este ejercicio de sistematización ha mostrado satisfacción con la propuesta de la asignatura, porque aprendió a elaborar diversos recursos con TIC, lo cual le podrá ayudar actualmente en su plan de estudios y en el futuros; además, se crea conciencia sobre la necesidad de cuidar el medio ambiente, utilizando material reciclable para 
otros recursos, como, por ejemplo, el teclado elaborado con cartón, plástico adhesivo y papeles de color; materiales que están al alcance de todas las personas.

Por tanto, se destaca la importancia de no abusar de los recursos materiales impresos; diversificar con recursos web abiertos y gratuitos para evitar la repetición de presentaciones en PowerPoint, antologías y material fotocopiado. El personal docente en la actualidad deberá capacitarse en nuevas formas de enseñar, con apoyo en los recursos, pues la generaciones actuales lo exigen, en el sentido de que manejen mucha información y eso hace que demanden nuevas tecnologías de enseñanza.

Es importante aprovechar los recursos de acceso abiertos que existen en internet, para actualizarse, dado que no hay que invertir presupuestariamente, o en algunos casos el costo es muy poco, además que es invertir para mejorar el proceso de enseñanza y aprendizaje.

Resulta oportuno brindar oportunidad al estudiantado que llega de la universidad, de realizar observación de aula, ya que esto beneficia, en el proceso, tanto al personal docente veterano como al novel, además de que se pueden generar sinergias interesantes para el fortalecimiento de capacidades pedagógicas que potencien el uso y aplicación de TIC, y de recursos tecnológicos tradicionales en las clases.

Es recomendable hacer uso del aula virtual que está al alcance del personal docente y estudiantes, como apoyo tecnológico al proceso de enseñanza y aprendizaje, para asignar tareas, fomentar el trabajo colaborativo, agregar material como tutoriales, para que el estudiantado se pueda orientar de cómo trabajar con algunos recursos y colocar los enlaces en las diferentes actividades programadas en las sesiones virtuales.

También resulta útil el uso de técnicas como palabra e imagen, para conocer las expectativas de estudiantes, además de que proponen mejoras al proceso de formación, en los futuros cursos que implementan a nivel de recursos didácticos.

\section{Referencias}

Araya, I. (2008). La formación dual y su fundamentación curricular. Revista Educación, 32(1) 45-61. Recuperado de http://revistas.ucr.ac.cr/index.php/educacion/article/viewFile/523/551

Araya, I. (2012). Construyendo el perfil por competencias para el profesional en Educación Comercial. Revista Electrónica Educare, 16(3), 203-226. Recuperado de http://www.redalyc. org/articulo.oa?id=194124728012

Cabero, J. (2007). Las necesidades de las TIC en el ámbito educativo: Oportunidades, riesgos y necesidades. Tecnología y Comunicación Educativas, 21(45), 4-19. Recuperado de http:// investigacion.ilce.edu.mx/tyce/45/articulo1.pdf 
doi: http://dx.doi.org/10.15359/ree.21-2.7

URL: http://www.una.ac.cr/educare

CORREO: educare@una.cr

Castillo, I. y Marín, C. (2009). Hacia una visión holística de la educación universitaria: El amor y el caos un proceso creativo para el aprendizaje. Revista Electrónica Educare, 13(1), 135-143. Recuperado de http://www.revistas.una.ac.cr/index.php/EDUCARE/article/ view/1481/1401

Cuevas, F. y Álvarez, V. (2014). Brecha digital en los docentes de secundaria en Costa Rica. En OEI (Ed.), Memorias del Congreso Iberoamericano de Ciencia, Tecnología, Innovación y Educación (pp. 1-25). Recuperado de http://www.oei.es/congreso2014/memoriactei/1215.pdf

Dewey, J. (1960). Experiencia y educación. Buenos Aires: Losada.

España, C. y Canales, A. (2013). La utilidad de las TIC para la promoción de aprendizajes en la educación superior. Revista Teoría de la Educación: Educación y Cultura en la Sociedad de la Información. 14(1), 189-227. Recuperado de http://www.redalyc.org/ pdf/2010/201025739010.pdf

Gallegos, R. (1999). Educación holística. Pedagogía del amor universal. México: Editorial Pax.

García, J. (2003). El potencial tecnológico y el ambiente de aprendizaje con recursos tecnológicos: Informáticos, comunicativos y de multimedia. Una reflexión epistemológica y pedagógica. Revista Actualidades Investigativas en Educación, 3(1), 1-24. doi: https://doi.org/10.15517/ aie.v3i1.9009

García, J. (2015). Principios pedagógicos universitarios. Buenos Aires: El Cid.

Jara, Ó. (2012). Sistematización de experiencias, investigación y evaluación: Aproximaciones desde tres ángulos. Revista Internacional sobre Investigación en Educación Global y para el Desarrollo, 1, 56-70 http://educacionglobalresearch.net/wp-content/uploads/02A-JaraCastellano.pdf

Lion, C. (2000). Mitos y realidades en la tecnologia educativa. En E. Litwin (Comp.), Tecnología educativa. Política, historias, propuestas (pp. 42-60). Buenos Aires, Argentinda.

Martínez, M. (2000). Análisis crítico de una metodología holística utópica. Acción Pedagógica, 9(1-2), 34-41. Recuperado de http://www.saber.ula.ve/bitstream/123456789/16986/1/ art5 12v9.pdf

Noguez, A. (2013). Los medios y recursos didácticos en la educación básica: Guía práctica para su planeación, elaboración y utilización. México. Trillas.

Ortiz, L. (2007). Campus virtual: La educación más allá del LMS. Revista de Universidad y Sociedad del Conocimiento, RU\&SC, 4(1), 1-7. Recuperado de http://www.uoc.edu/rusc/4/1/dt/esp/ ortiz.pdf 
Pardo, L. (2001). La educación como proceso holístico, la comunicación participativa y la motivación, principales elementos del cambio. Aquichan. 1(1), 23-29. Recuperado de http://aquichan.unisabana.edu.co/index.php/aquichan/article/view/9/15

Pérez, G. (1994). Investigación cualitativa. Retos e interrogantes (6ª ed.). Madrid: La Muralla.

Ruiz, A. A. (2015). Desarrollo tecnológico y usoeducativo de las TIC:Visión crítica dela modernidad. En F. E. Ramas (Coord.), TIC en educación: Escenarios y experiencias (pp. 15-46). España: Ediciones Díaz de Santos.

Ruiz, M. A. (2007). Primera aproximación hacia una pedagogía de la resocialización. Nómadas. Revista Crítica de Ciencias Sociales y Jurídicas, 16(2): 151-160. Recuperado de https:// revistas.ucm.es/index.php/NOMA/article/view/NOMA0707220151A/26495

Salas, R., Rojas, G. y Jiménez, C. (1998). Un proyecto de educación holística. Innovación educativa, $8,71-82$.

Soler, R., Soler J.r. y Araya, I. (En prensa). Subjects in the blended learning model design. Theoretical-methodology. Procedica-Social and Behanvioral Sciences.

Tabares, J. F., Molina, V. A. y Cuervo, I. D. (2014). Guía para la sistematización de experiencias. Recuperación del saber y del ser en el ocio, deporte, educación física y actividad física. Medellín: Universidad de Antioquia. 